\title{
Monitoring of Seasonal Flooding in the Okavango Delta using EO-1 Data
}

\author{
Amy L. Neuenschwander ${ }^{1}$, Melba M. Crawford ${ }^{1}$, Susan Ringrose ${ }^{2}$ \\ ${ }^{1}$ Center for Space Research, University of Texas at Austin \\ 3925 W. Braker Lane, Suite 200, Austin, TX $78759-5321$ (512) 471-5573 \\ crawford@csr.utexas.edu \\ ${ }^{2}$ Harry Oppenheimer Okavango Research
}

\begin{abstract}
Located in northwestern Botswana and fed by the Okavango River originating in Angola's western highlands, the Okavango Delta is the world's largest inland delta. The floodwaters require approximately nine months to flow from the source to the bottom of the Delta due to the extremely low topographic relief. During the peak of flooding, the delta's area can expand to over 16,000 square kilometers, almost doubling the 9,000 square kilometers during the dry season. Investigation of the hydrologic cycle of the Okavango is relevant to studies ranging from fundamental research in climate change to exploration for groundwater to alleviate water shortages faced by local villages. Because the extent and inaccessibility of many areas of the Delta, the application of remote sensing technology is extremely attractive, if it can be shown to effectively map important landcover and geomorphological characteristics (or their surrogates). While results of previous investigations of the capability of multispectral sensors for characterizing drying gradients [1] were promising, the increased dynamic range and additional bands of ALI data potentially provide greater capability for mapping flooding events and characterizing the ecological changes that are rapidly occurring in the Okavango Delta due to climate change and anthropogenic impacts. Further, Hyperion hyperspectral data should provide even greater discrimination of complex vegetation assemblages and improved characterization of seasonal changes in spectral response of vegetation to the annual flooding event. A series of eight near cloud-free EO-1 ALI and Hyperion acquisitions were obtained over Chief's Island (located in the center of the Delta) spanning the 2001 dry and flooding seasons. The extent of the flood event was mapped using $\mathrm{ALI}$, and the seasonal variation in spectral response of vegetation was determined using ALI and Hyperion. The capabilities of ALI and Hyperion for mapping landuse/landcover change in the Delta are being investigated and compared to Landsat.
\end{abstract}

\section{Acknowledgements}

This work was supported by the National Aeronautics and Space Administration, under the EO-1 program (NCC5463) and the Army Research Office, under the Terrestrial Sciences Program (DAAG55-98-1-0287).

\section{INTRODUCTION}

The Okavango Delta located in northwest Botswana is one of the world's largest inland alluvial fans and is a critical environment for a wide variety of wildlife. The Delta is comprised of several characteristic features; the panhandle, permanent swamps, seasonal swamps, and permanent islands. The topographic gradient for the panhandle is 1:5570 and 1:3400 for the lower alluvial fan [3]. The floodwaters from the Okavango River require approximately nine months to flow from the source to the bottom of the Delta due to the extremely low topographic relief. The majority of the inflow (approximately 97\% [4]) from the Okavango River is lost through evaporation. Small, elevated areas do exist within the Delta as forested islands, whereas grasslands make up the floodplain vegetation during the dry season. The herbaceous vegetation in the Okavango consists of approximately $5000 \mathrm{~km}^{2}$ which are permanently flooded throughout the year while another $11,000 \mathrm{~km}^{2}$ are seasonally flooded grasslands [5].

Ringrose et al. [1] used Landsat TM data to study drying gradients in three areas of the Okavango as part of the SAFARI2000 project in southern Africa (www.safari.gecp.virginia.edu). Focusing on characterizing geomorphic-soils relationships and evaluating spatial/spectral characteristics in vegetation in floodplains and current and previously existing islands, the study involved a combination of statistical classification of TM data combined with interpretation of high resolution aerial photography and field studies. The potential of Landsat TM imagery was also investigated for characterizing evapotransporation in the Delta [2], where results were inconclusive, but indicated that leaf water content indices developed for northern forests are not generally applicable. The current study is focusing on evaluating the potential of a multi-temporal series of ALI multispectral and panchromatic data and hyperspectral Hyperion for mapping seasonal flooding events and associated responses of vegetation and landforms in the Delta.

\section{REMOTELY SENSED DATA}

The NASA EO-1 satellite acquired a series of eight ALI and Hyperion data sets from April to August 2001. Since the ALI and Hyperion sensors on the EO-1 satellite are experimental and the data provided are not in operational level, a significant amount of pre-processing is required to construct a time series of ALI data. Variable 
striping occurs due to bad detectors and anomalous events. Data are acquired in four adjacent strips though individual telescopes, thereby necessitating mosaicking for largescale studies. Further, adjacent strips have scene specific geometry due to the ability to point the instrument. Individual bands are only roughly co-aligned within each strip, which is insufficient for many landcover classification applications. In this study, the effect of striping is ameliorated by replacing affected bands by the average of the values of adjacent pixels on each scan line. Interband registration is accomplished relative to a selected reference band. Data are upsampled, and sample correlations between corresponding patches of data are computed on a predetermined grid between all bands and the reference band. The resulting best affine transformations are computed to coalign the bands. Then, the four strips for each acquisition of data are mosaicked and georeferenced to a Landsat $\mathrm{ETM}^{+}$base map using the overall 2-D affine transformations to accommodate the composite non-integer shifts and rotations for band alignment, mosaicking, and georeferencing. Similarly, Hyperion data required destriping, alignment of the VNIR/SWIR spectral data, and georeferencing. Band 9 of a subset of the Okavango Delta from Chief's Island to Maun for each ALI scene that was analyzed is shown in Fig. 1.

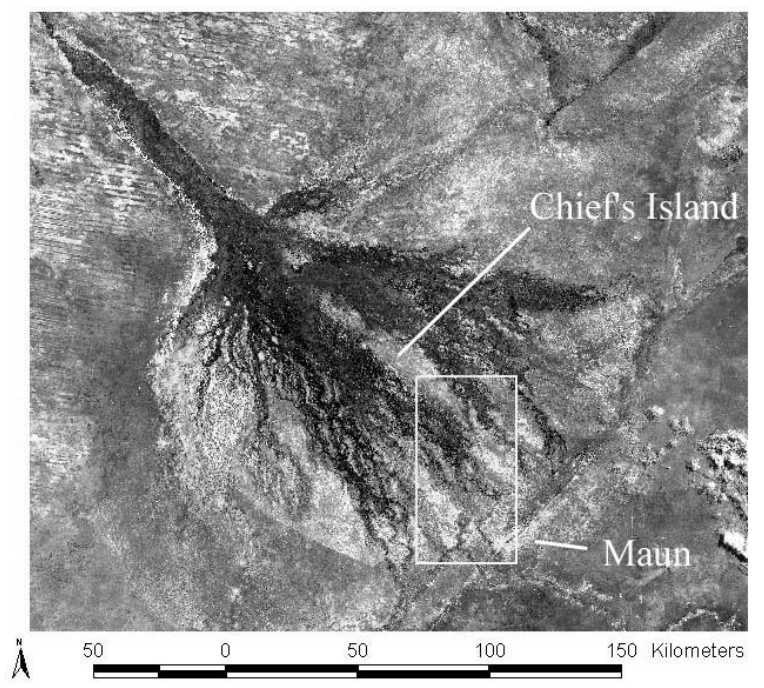

Figure 1. Landsat image of the Okavango Delta with ALI subset coverage area shown in white box.

The four ALI images chosen for subsequent analysis were acquired on 31 May 2001, 16 June 2001, 11 July 2001, and 19 August 2001, shown in Fig. 2. The peak flooding in the Okavango actually occurs during the dry season due to the subtle topographic change over the extent of the delta, so scenes are typically cloud-free. The seasonal effects can be seen not only in the increased flooding in the southern portion of the Okavango Delta, but conversely by the changes in the local vegetation.

\section{RESULTS}

For flood mapping, the ALI data sets were initially classified using a maximum likelihood classifier and three eco-regions: water, permanent swamp, and intermittent marsh were extracted for spatial analysis. The permanent swamp class consists of marsh lands that are flooded throughout the year. The floodplain vegetation in the Okavango consists of grasses which are flooded seasonally. A seasonally inundated marsh class, or intermittent marsh, was identified from the remotely sensed imagery and is believed to be an indicator of impending flooding as these areas are typically flooded in the subsequent image. The evolution of the flooding event are shown in Table 1 in terms of changes in area of the respective land cover classes.

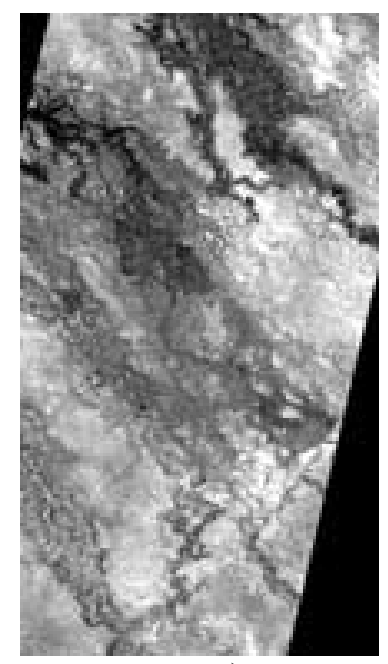

a)

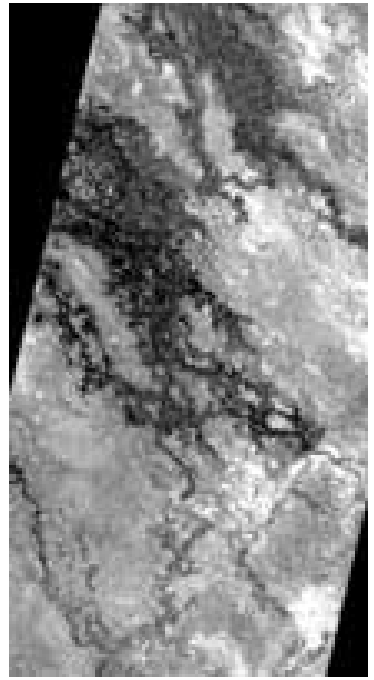

c)

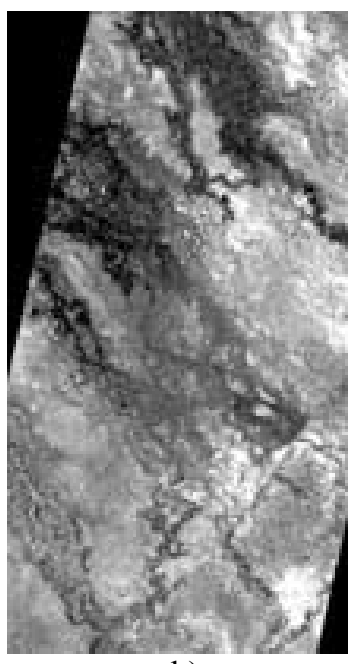

b)

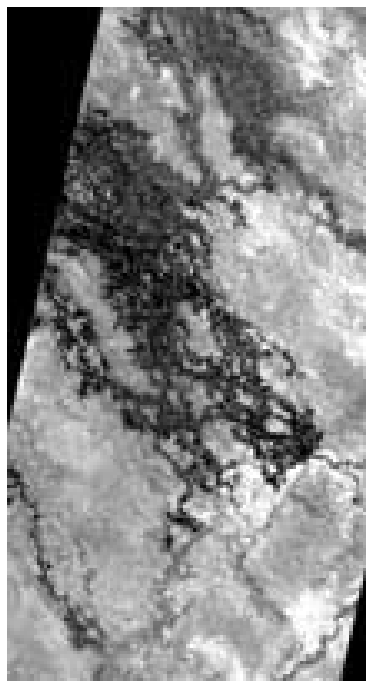

d)
Figure 2. ALI band $9(2226 \mathrm{~nm})$ mosaic of Okavango Delta for a) May 31, 2001 b) June 16, 2001 c) July 11, 2001 d) August 19, 2001 
Table 1. Computed land cover area based on classification of ALI data throughout the 2001 flooding season.

\begin{tabular}{|l|c|c|c|}
\hline Date & $\begin{array}{c}\text { Water } \\
\left(\mathrm{km}^{2}\right)\end{array}$ & $\begin{array}{c}\text { Permanent } \\
\text { Swamp } \\
\left(\mathrm{km}^{2}\right)\end{array}$ & $\begin{array}{c}\text { Intermittent } \\
\text { Marsh }\left(\mathrm{km}^{2}\right)\end{array}$ \\
\hline May 31 & 27.24 & 189.58 & 78.24 \\
\hline June 16 & 50.56 & 185.04 & 114.56 \\
\hline July 11 & 173.95 & 133.35 & 51.45 \\
\hline August 19 & 169.52 & 183.58 & 106.11 \\
\hline
\end{tabular}

The effects of flooding can be seen in the total land cover through the sequence of ALI data with the peak flooding occurring in August. Figures 3 and 4 show the spectral responses for two landcover types, permanent swamp and grasses. For the ALI subset, the predominance of the permanent swamp occurs near the northern portion of the image. The peak reflectances for permanent swamp occur on May 31, indicating that the peak water level in the northern portion of the scene occurred in June and July. The spectral responses computed for grass indicates a senescence of vegetation progressing through the dry season indicated by higher reflectances with the most significant separation occurring in the mid-infrared region.

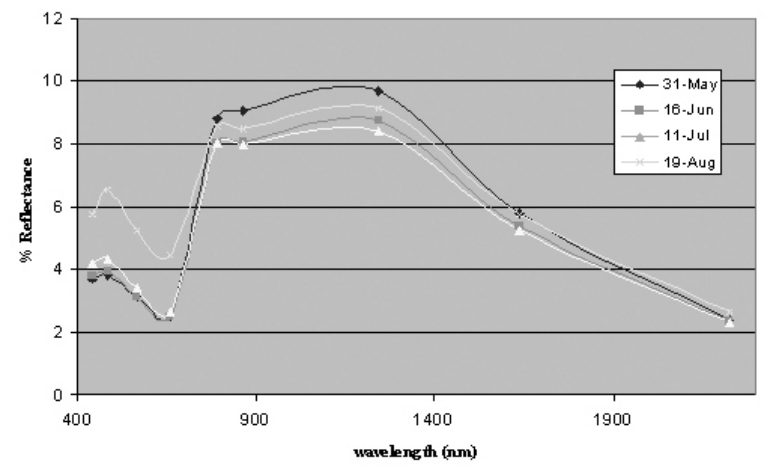

Figure 3. Spectral signatures of permanent marsh for sequence of ALI data.

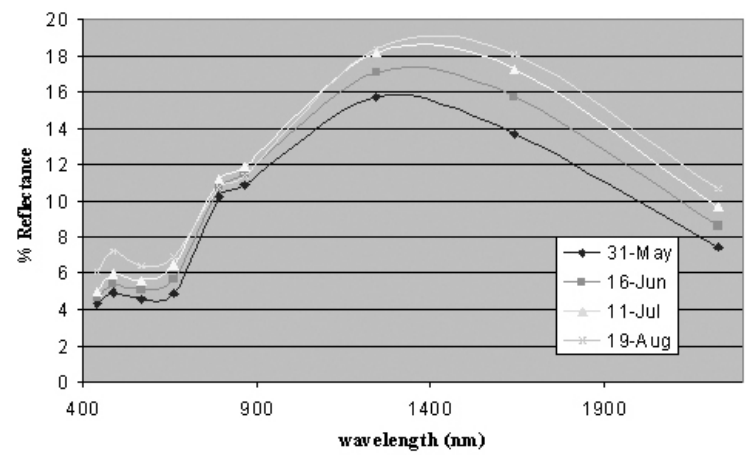

Figure 4. Spectral signatures of grasses for sequence of ALI data.

Figure 5 illustrates the improved dynamic range of the radiometric properties for the ALI and Hyperion instruments compared to the Landsat $\mathrm{ETM}^{+}$for grass. The ALI radiance values are consistent with the radiances of the full spectrum from Hyperion, whereas the Landsat $\mathrm{ETM}^{+}$values are flat through the visible region.

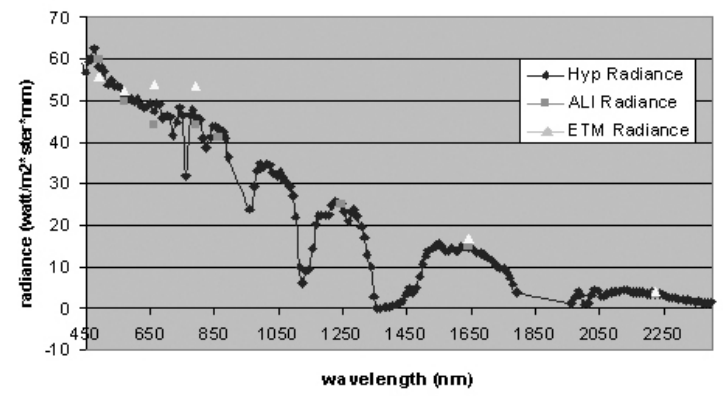

Figure 5. Sensor comparison for ALI, Hyperion, and Landsat ETM for near concurrent August 2001 data.

\section{CONCLUSIONS AND FUTURE WORK}

Evaluation of a multi-temporal series of ALI multispectral data demonstrates that it is an effective means for mapping seasonal flooding events and associated responses of vegetation and landforms in the Okavango Delta. Spectral data acquired from a low altitude helicopter campaign will be compared to ALI and Hyperion for cal/val studies and used to support upscaling studies based on multiresolution data from EO-1 and MODIS. During the ongoing study, the potential of Hyperion data for improved discrimination of classes will also evaluated using new algorithms for feature extraction and classification developed by the UT Center for Space Research.

\section{REFERENCES}

1. S. Ringrose, S., A. Jelema, P. Huntsman-Mapila, L. Baker, and K. Brubaker," Use of remotely sensed data to assess the significance of drying gradients in the Okavango Delta, Botswana," Int. J. Remote Sensing, in review.

2. S. Ringrose, W. Matheson, A. Jelema, M. Ashworth, "Techniques for assessing water uptake and potential loss by riparian trees in the distal Okavango delta, Botswana," Applied Geography, in review.

3. T.S. McCarthy, M. Barry, W.N. Ellery, H. Heister, C.L. Merry, H. Ruther, and H. Sternberg, "The gradient of the Okavango fan, Botswana, and its sedimentological and tectonic implications", Journal of African Earth Sciences, Vol. 24, No. 1/2, pp. 65-78, 1997.

4. T. Scudder, R.E. Manley, R.W. Coley, R.K. Davis, J. Green, G.W. Howard, S.W. Lawry, D. Martz, P.P. Rogers, A.R.D. Taylor, S.D. Turner, G.F. White, E.P. Wright, "The IUCN Review of the Southern Kavango Integrated Water Development Project", Gland, Switzerland: IUCN - The World Conservation Union, 1993.

5. The Kalahari Conservation Society Online Fact Page, http://www.delin.org/kalahari/facts.html, Summer 2000 